\title{
Augmentation mammaplasty by superolateral thoracic flap: a case report
}

\author{
Elise Lupon ${ }^{1,2,4^{*}}$, Benoit Chaput ${ }^{1,4}$ and Thomas Meresse $e^{1,3,4}$
}

\begin{abstract}
Background: The lateral chest wall is intimately associated with the esthetics of the breast. Patients with massive weight loss often have excess skin and fat in the lateral thoracic region causing functional, esthetic, and psychological discomfort. In addition, the breasts exhibit extreme ptosis after weight loss due to a reduction in volume and projection that is exacerbated by qualitative changes in the skin, with loss of its natural elasticity. This article describes a reliable new technique for simultaneous autologous breast augmentation and lateral thoracic dermolipectomy to provide autologous tissue for breast augmentation and simultaneous rejuvenation of the chest wall.
\end{abstract}

Case presentation: A 30-year-old Caucasian woman who had lost $58 \mathrm{~kg}$ after bariatric surgery had major skin excess sequelae combined with major breast ptosis. She wanted to correct her brachial and lateral thoracic skin and fat excess, as well as rejuvenate her breasts. The lateral thoracic panicle present was harvested and transposed in the retroglandular plane to perform autologous breast augmentation with lateral thoracic dermolipectomy.

Results: The patient was totally healed and complication-free at day 15 . Both esthetic results and patient satisfaction were good at 6 months post-surgery.

Conclusions: Superolateral thoracic flap augmentation mammaplasty during thoracic dermolipectomy is a simple and safe procedure for selected patients. Durable and natural autologous breast augmentation may be achieved in a single step without the need for a breast implant, while rejuvenating the thoracic region.

Keywords: Bariatric surgery, Autologous breast augmentation, Fat compartment, Lateral chest wall, Superolateral thoracic flap

\section{Introduction}

One of the main issues in post-bariatric plastic surgery is to resect the dermolipomatous excess and to improve body contouring. Brachioplasty, abdominoplasty, cruroplasty, rhytidectomy, mammaplasty, and mastopexy are procedures that enhance self-esteem and reduce the health-related problems of these patients [1]. Ptosis and breast volume loss are common characteristics in women

\footnotetext{
*Correspondence: elupon@mgh.harvard.edu

${ }^{1}$ Service de Chirurgie Plastique et Reconstructrice, CHU Toulouse

Rangueil, 1 Avenue Jean Poulhès, TSA 50032, 31059 Toulouse Cedex 9, France

Full list of author information is available at the end of the article
}

who have massively lost weight after bariatric procedures, and their correction is a frequent request [2].

Patients with massive weight loss also represent a group with distinct issues concerning the lateral chest wall [3]. The latter has the shape of a triangle with its apex at the axilla. It can be divided into three subunits: the axilla, breast, and chest wall. The lateral chest wall is intimately associated with the esthetics of the breast but is much neglected and rarely addressed as a separate unit [3]. Failure to address this area can have esthetic consequences and be a source of distress for patients, because the lateral chest wall and axilla cannot be easily hidden in certain clothing, such as bras and bathing suits.

In this article we describe a technique to address these issues. The lateral thoracic panicle juxtaposed to the original author(s) and the source, provide a link to the Creative Commons licence, and indicate if changes were made. The images or other third party material in this article are included in the article's Creative Commons licence, unless indicated otherwise in a credit line to the material. If material is not included in the article's Creative Commons licence and your intended use is not permitted by statutory regulation or exceeds the permitted use, you will need to obtain permission directly from the copyright holder. To view a copy of this licence, visit http://creativecommons.org/licenses/by/4.0/. The Creative Commons Public Domain Dedication waiver (http://creativeco mmons.org/publicdomain/zero/1.0/) applies to the data made available in this article, unless otherwise stated in a credit line to the data. 
breasts can easily be used as an adipofascial and superolateral thoracic (SLT) flap for breast augmentation. These SLT flaps on the lateral surface of the chest remain pedicled to their upper bloodstream and are buried subglandularly in the breast, creating an autologous breast augmentation.

We present the case of a young post-bariatric patient who received autologous breast augmentation with this lateral thoracic fat and skin excess at the same time as bilateral brachioplasty.

\section{Case presentation}

\section{Patient and operative indication}

A 30-year-old Caucasian woman consulted for surgical correction of excess brachial skin and fat and breast ptosis. According to the Regnault's classification, she presented a grade II ptosis when she had her arms along her body. She wanted her breasts to be enlarged but without implants. She had undergone bypass bariatric surgery in 2015 for morbid obesity [body mass index (BMI) 51]. She had no major history other than a malabsorption syndrome following surgery. She was a nonsmoker. The loss of $58 \mathrm{~kg}$ had caused significant excess skin and fat. After stabilizing her weight (BMI 29), she underwent surgery to repair her abdominal and back weight loss sequelae 2 years after her bypass in 2017 thanks to a body lift.

On clinical examination, there was breast ptosis with a significant loss of projection and bilateral brachial excess skin, which is classic in this post-bariatric context. A major lateral thoracic excess causing significant discomfort was noted. Excess skin and subcutaneous tissue in the lateral chest wall was assessed by means of a pinch test to determine the available width of this donor flap. Considering these findings, we proposed brachioplasty associated with breast augmentation and intramammary burial of the excess tissue in the lateral thoracic region. The patient was informed of the expected higher degree of scarring. She was informed that the scars would extend from the inside of the elbow to the inside edge of the arm (brachioplasty), from the lateral surface of the thorax to the breast base (removal of excess lateral thoracic tissue and mammary burial), and that she would have a long submammary scar (necessary for positioning the flap).

A maneuver that must be performed to convince both surgeon and patient of the eligibility for true SLT flap or augmentation mammaplasty by superolateral thoracic (SLT) flap is reclination of the lateral thoracic skin in the breast test (Fig. 1).

\section{Surgical technique}

Preoperative drawing must be performed in a standing position (Fig. 2). Under general anesthesia, the patient is

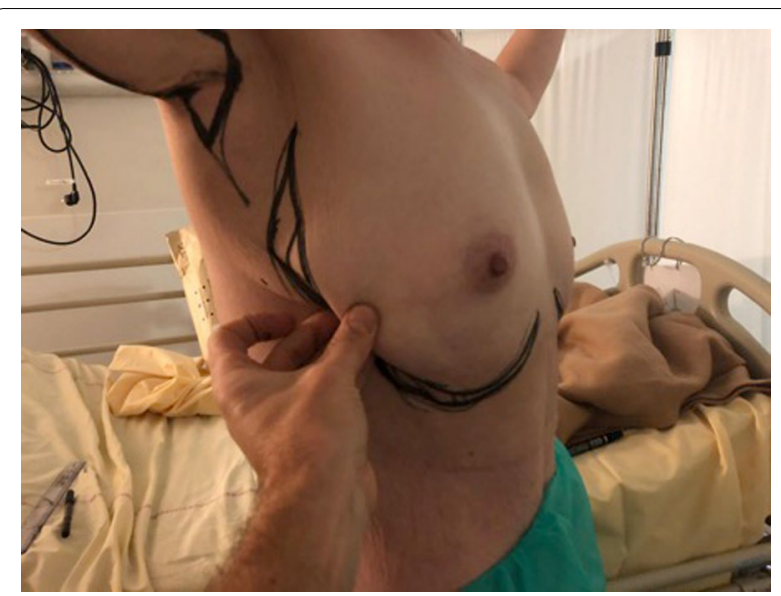

Fig. 1 Reclination test of excess lateral fat skin and thoracic skin in breast
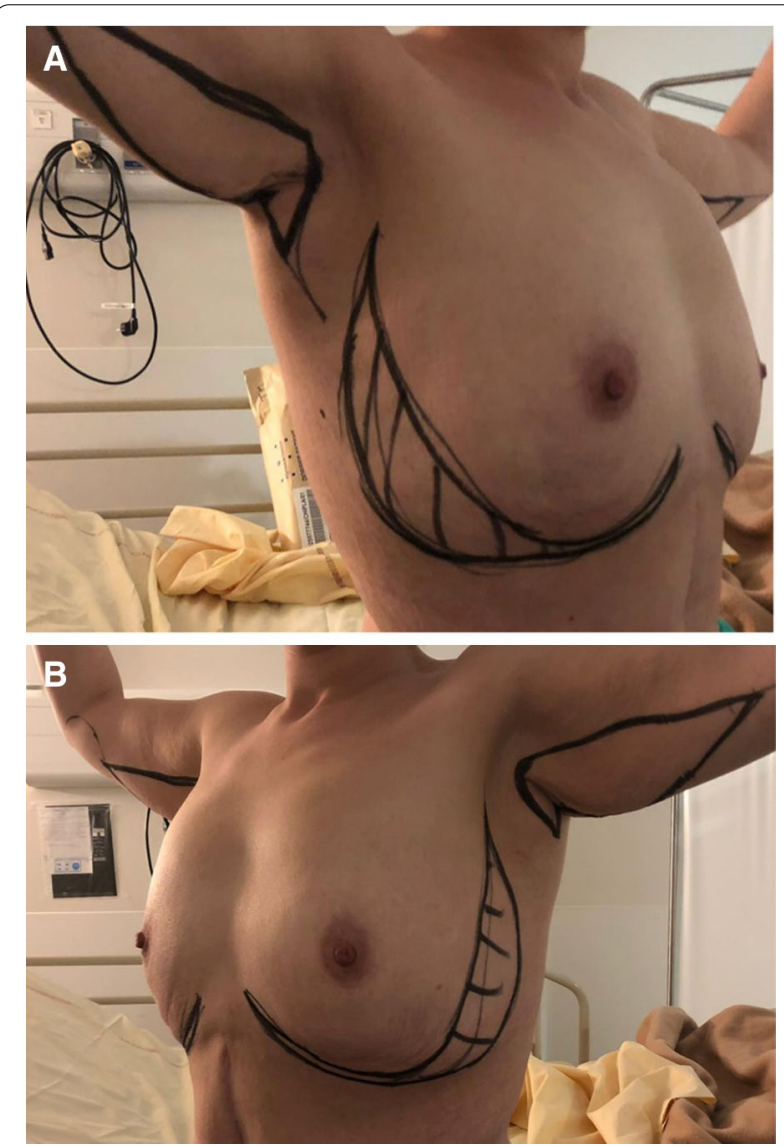

Fig. 2 Preoperative drawing of excess skin and fat areas to be treated. Patient is standing. A Right view. B Left view

positioned supine on the operating table with both arms supported on arm boards abducted to $90^{\circ}$. The first step is classic brachial dermolipectomy. After a skin incision 
on the brachial drawing, de-epithelialization is performed with an electric scalpel. After hemostasis, closure is performed in two planes with $3 / 0$ resorbable monofilament thread. This first step is carried out on both sides.

The second step consists of lateral thoracic skin resection, delimitation, and burial of the thoracic flaps. The shape of the resection must be confirmed by making a frame with staples. This frame allows the upper part of the design to be adapted and to create a continuity with the brachial dermolipectomy design with a cutaneous area preserved in an " $\mathrm{S}$ " shape between the two. This prevents a bridle when the arm is raised. The drawing is traced back to the frame, and the modeling staples can then be removed.

De-epithelialization of the area is carried out with coagulating forceps. The flap is detached but remains attached to the bank on the breast side (Fig 3). During this maneuver, the external mammary vascular network must be preserved (Fig. 4). The flap is detached from the thoracic and pectoral planes to about half of the outer side of the breast. This flap is then buried into the breast and sutured deep down with 2/0 resorbable stitches (Fig. 5). Sutures are then made to reattach the submammary and external mammary groove, taking in the two edges and the periosteum of the corresponding rib with $2 / 0$ resorbable stitches. This deep mooring is essential for the outcome to be satisfactory. Sutures are made between these pressure points with transparent resorbable $3 / 0$ monofilament thread and an intradermal overlock with the same thread. This second step is carried out in the contralateral thoracic region. Care must be taken to ensure good symmetry at the end of the procedure (Fig. 6). No drainage system is required. To ensure better postoperative analgesia, all scars are infiltrated with ropivacaine.

\section{Postoperative care and results}

The patient was hospitalized for 1 day and was allowed to leave the day after surgery. The postoperative course was uneventful, with no breast skin necrosis, no hematoma, and no seroma or infections. At 15 days, the patient did not have any scarring disorders and she was already satisfied with the result. At 6 months, she no longer had areolar ptosis with an areola above the fold under the breast when she had her arms along the body. Under the inframammary fold, a persistent slight glandular descent was noticeable but allowed to keep a natural aspect, according to the patient. She was very satisfied with the result and reported feeling much more comfortable from a functional and body image point of view (Fig. 7).
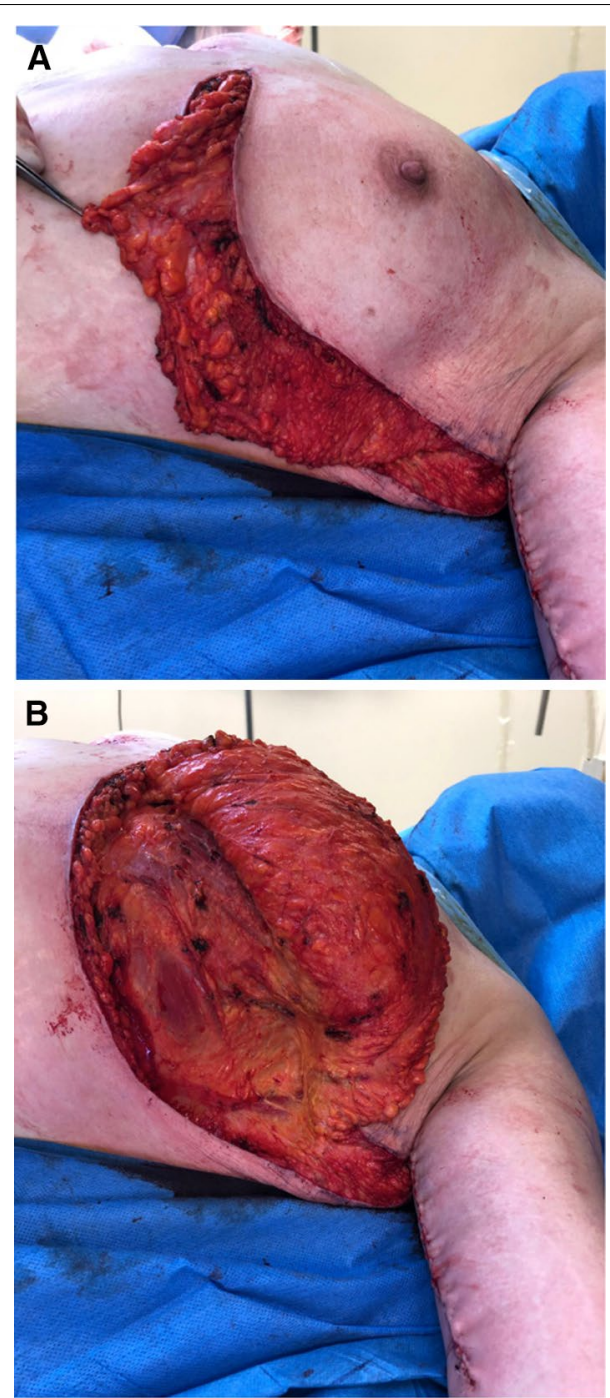

Fig. 3 Detachment of the flap that is supplied by the external mammary vascular network. It is then attached to the edge on the breast side. $\mathbf{A}$ View of pedicle flap released from its distal attachments. B View of reclined pedicle flap

\section{Discussion}

Plastic surgery after massive weight loss aims at resecting skin excess, facilitating personal hygiene to increase satisfaction with the body, improving sexual, social, and interpersonal relationships, increasing self-esteem, and providing better quality of life [4]. Patients with postbariatric lateral chest wall deformities defined preoperatively and addressed directly have the greatest likelihood of obtaining a satisfactory esthetic outcome [3]. The augmentation mammaplasty technique by SLT flap described here allows the surgeon to perform symmetric augmentation of the breasts by using autologous 

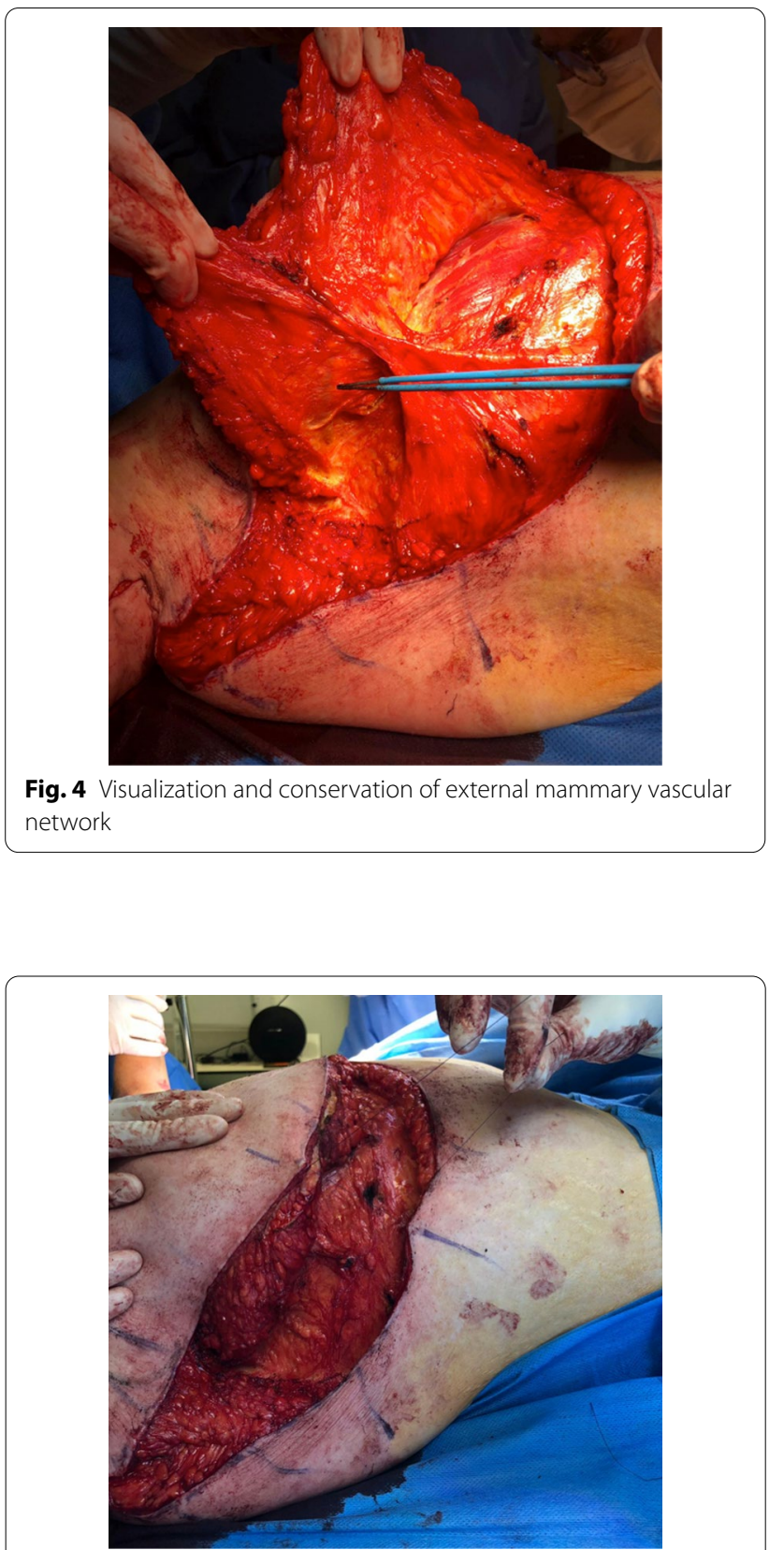

Fig. 5 Burial of flap in breast and deep suturing

tissue in patients with an unsightly excess of lateral thoracic skin and fat.

As the procedure is new, the patient stayed the first night after the operation in hospital in order to prevent any complications. However, given the low level of postoperative pain relieved by ropivacaine, the absence of expected complications with this type of surgery, and the lack of necessity to monitor the flap, outpatient hospitalization is probably sufficient.

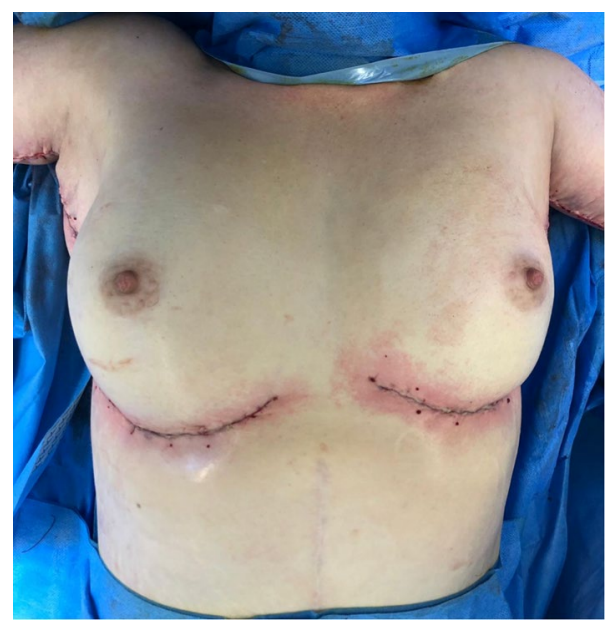

Fig. 6 Result at end of procedure, symmetrical

Breast augmentation with or without mastopexy has regained its position as one of the most popular procedures in esthetic surgery. Various augmentation mastopexy techniques have been described to improve breast shape and increase their volume [5-7]. They are considered difficult to plan with results that are not easy to predict [8-10]. In our case, the placement of the breast flaps made it possible to reshape the breast sufficiently and to postpone classic mastopexy with its incumbent periareolar scars. However, our procedure cannot be performed at the same time as an inverted-T mastopexy in the event of major ptosis (Regnault stage IV). While augmentation with breast implants is still the simplest and safest method, complications such as capsular contracture, rippling, periprosthetic atrophy, implant deflation, and implant visibility and palpability may still occur. The use of autologous tissue for breast augmentation has several advantages over implants. Lateral thoracic tissue is often discarded, yet our technique allows it to be recycled for breast enhancement. There is no risk of capsular contracture or the other aforementioned problems, as the breasts are augmented with autologous tissue.

Breast augmentation with autologous tissue also creates a more natural feeling of having real breast tissue. Lipofilling can be performed subsequently if the volume of tissue is insufficient. SLT flap augmentation mammaplasty is not the only breast augmentation technique with autologous tissue. For example, mammaplasty by reverse abdominoplasty has been used successfully for rejuvenating the abdomen and the breast simultaneously [11-15]. In the augmentation mammaplasty by reverse abdominoplasty (AMBRA) technique [11], the upper abdominal panicle juxtaposed inferiorly to the breasts is poised for easy repositioning as adipofascial 

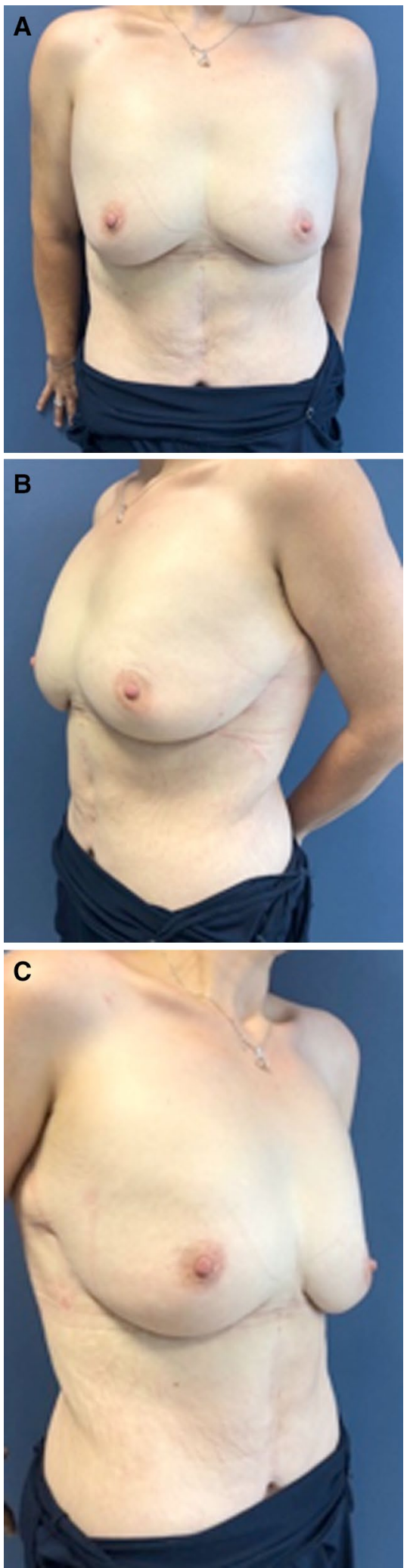

Fig. 7 Result at 6 months. A Front view. B Left-side view. C Right-side view flaps to allow augmentation mammaplasty. Other autologous techniques exist such as bilateral de-epithelialized transverse rectus abdominis musculocutaneous flaps, extended transverse rectus abdominis musculocutaneous flaps, pedicled perforator flaps, and autologous fat transplantation, which are considered to have the same level of performance as synthetic implants [16-21].

Concerning the specific treatment of excess lateral thoracic fat and skin, few techniques have been reported to date. Some authors advocate an algorithmic approach to their surgical treatment, including transfer of autologous tissue, liposuction, fat injection, and direct excision. Cryolipolysis has also been used successfully to reduce discomfort from residual lateral chest wall fat in postmastectomy patients [22]. The treatment of excess lateral thoracic fat and skin simultaneously with breast augmentation has been the subject of very few publications [23, 24].

Our technique is particularly adapted to E3 deformities in the classification of Bar-Meir et al. [3], involving an excess of both skin and fat of the lateral chest wall, usually involving all three subunits. Although initially designed for esthetic purposes, it has proven valuable for reconstructive purposes in appropriately selected cases [23]. Lateral thoracic tissue can be transferred to correct defects in treated or reconstructed breasts or to obtain symmetry. It has the advantage of combining autologous breast augmentation with an improvement in the lateral wall chest in a single procedure while keeping the groove under the breast. Its main theoretical risk is fat necrosis and cyst formation [25], hence the importance of preserving the external mammary vascular network for the vitality of the cutaneous sheath and breast fat, on the one hand, and of respecting the direct cutaneous perforators from the lateral thoracic, on the other. The flap is wide, which guarantees its vascular safety. The decision to lift the flap on a superior rather than an inferior external pedicle was considered carefully. This allows better anchoring of the scar and better fixation of the highly mobile fold under the breast in patients who have lost weight massively. This upper pedicle allows the flap to be turned over and folded to increase the projection of the breast.

Some authors [26] have demonstrated that the lateral thoracic region contains a fat compartment that is unique in its anatomical boundaries. Further vascularization of these lateral thoracic flaps has been described [24] and the pedicled fasciocutaneous flap can be based, as in this case, on direct cutaneous perforators from the lateral thoracic or intercostal arteries, or on septocutaneous perforators from the thoracodorsal or long thoracic arteries. According to the algorithm described by Levine et al. in 2015 [23] that facilitates the choice between 
the different pedicles, the flap must be centered over the fourth interspace if the tissue is needed for augmentation and if flap de-epithelialization is planned. Finally, the scar is less visible with this technique than with standard lateral thoracic dermolipectomy. Indeed, with lateral thoracic dermolipectomy, the vertical scar along the thorax is mandatory to remove any excess thoracic skin. Our technique allows the scars to be positioned advantageously on the external and submammary grooves, resulting in a much more esthetic appearance.

\section{Conclusions}

SLT flap augmentation mammaplasty is a simple new procedure for patients with lateral thoracic skin laxity and adiposity who desire autologous tissue breast augmentation with or without mastopexy combined with rejuvenation of the lateral chest wall. The increased lateral flank scarring in continuity with a simultaneous brachioplasty incision is well tolerated by patients, with the additional benefit of reducing flank fullness and avoiding the more visible scars associated with mastopexy.

\section{Abbreviations}

SLT: Superolateral thoracic flap; AMBRA: Augmentation mammaplasty by reverse abdominoplasty.

\section{Acknowledgements}

Not applicable.

\section{Authors' contributions}

EL had the initiative of this publication and wrote the manuscript, and participated in the surgery, study concept and design, data acquisition, manuscript preparation, and manuscript review. TM was the main surgeon and had the idea of the surgical innovative technique, study concept and design, data acquisition, manuscript preparation and manuscript review, and all surgical procedures. BC gave some technical tips and proofread the manuscript. All authors read and approved the final manuscript.

\section{Funding}

None.

\section{Availability of data and materials}

Available (ask the corresponding author).

\section{Declarations}

Ethics approval and consent to participate Not required.

\section{Consent for publication}

Written informed consent was obtained from the patient for publication of this case report, as well as the accompanying images. A copy of the written consent is available for review by the Editor-in-Chief of this journal.

\section{Competing interests}

The authors declare that they do not have any competing interests.

\section{Author details}

'Service de Chirurgie Plastique et Reconstructrice, CHU Toulouse Rangueil, 1 Avenue Jean Poulhès, TSA 50032, 31059 Toulouse Cedex 9, France. ${ }^{2}$ Department of Plastic and Reconstructive Surgery Research, Massachusetts General Hospital, 55 Blossom Street, Boston, MA 02114, USA. ${ }^{3}$ Department of Plastic
Surgery, Institut Universitaire du Cancer de Toulouse Oncopole, Institut Claudius Regaud, 1, Avenue Irène Joliot-Curie, 31059 Toulouse, France. ${ }^{4}$ Department of Plastic surgery, University Toulouse III Paul Sabatier, Toulouse, France.

Received: 9 December 2020 Accepted: 10 September 2021

Published online: 17 November 2021

\section{References}

1. Scheufler O, Erdmann D. Current concepts and trends in post-bariatric plastic surgery. Chirurg. 2007;78(4):316-25.

2. Song AY, Jean RD, Hurwitz DJ, Fernstrom MH, Scott JA, Rubin JP. A classification of contour deformities after bariatric weight loss: the Pittsburgh Rating Scale. Plast Reconstr Surg. 2005;1 16(5):1535-44; discussion 1545-6.

3. Bar-Meir ED, Lin SJ, Momoh AO, et al. The lateral chest wall: a separate aesthetic unit in breast surgery. Plast Reconstr Surg. 2011;128:e626-34.

4. Cintra W Jr, Modolin ML, Gemperli R, Gobbi Cl, Faintuch J, Ferreira MC. Quality of life after abdominoplasty in women after bariatric surgery. Obes Surg. 2008;18(6):728-32.

5. Regnault P. The hypoplastic and ptotic breast: a combined operation with prosthetic augmentation. Plast Reconstr Surg. 1996;37(1):31-7.

6. Rubin JP, Khachi G. Mastopexy after massive weight loss: dermal suspension and selective auto-augmentation. Clin Plast Surg. 2008;35(1):123-9.

7. Lockwood T. Reduction mammaplasty and mastopexy with superficial fascial system suspension. Plast Reconstr Surg. 1999;103(5):1411-20.

8. Losken A. Breast reshaping following massive weight loss: principles and techniques. Plast Reconstr Surg. 2010;126(3):1075-85.

9. Migliori FC, Gabrielli A, Rizzo R, et al. Breast contouring in postbariatric patients: a technique selection algorithm. Obes Surg. 2010;20(5):651-6.

10. Akyurek M. Short scar reduction mammaplasty in the bariatric patient. Ann Plast Surg. 2011;66(6):602-6.

11. Zienowicz RJ, Karacaoglu E. Augmentation mammaplasty by reverse abdominoplasty (AMBRA). Plast Reconstr Surg. 2009;124(5):1662-72.

12. Baroudi R, Keppke EM, Carvalho CG. Mammary reduction combined with reverse abdominoplasty. Ann Plast Surg. 1979;2:368-73.

13. Berrino P, Campora E, Leone S, Santi P. Correction of type II breast deformities following conservative cancer surgery. Plast Reconstr Surg. 1992;90:846-53.

14. Dagregorio G, Darsonval V. Aesthetic surgery techniques after excision of dermatofibrosarcoma protuberans: a case report. Br J Plast Surg. 2005;58:556-60.

15. Hurwitz DJ, Agha-Mohammadi S. Postbariatric surgery breast shaping the spiral flap. Ann Plast Surg. 2006;56:481-6.

16. Lai YL, Yu YL, Centeno RF, Weng CJ. Breast augmentation with bilateral deepithelialized TRAM flaps: an alternative approach to breast augmentation with autologous tissue. Plast Reconstr Surg. 2003;112:302-8; discussion 309-311.

17. Landuyt KL, Hamdi M, Blondeel P, Monstrey S. Autologous breast augmentation by pedicled perforator flaps. Ann Plast Surg. 2004;53:322-7.

18. Kwei S, Borud LJ, Lee BT. Mastopexy with augmentation after massive weight loss. Ann Plast Surg. 2006;57:361-5.

19. Hamdi M, Landuyt KV, Frene BD, Roche N, Blondeel P, Monstrey S. The versatility of the intercostal artery perforator (ICAP) flaps. J Plast Recontstr Aesthet Surg. 2006;59:644-52.

20. Pulagam SR, Poulton T, Mamounas EP. Long-term clinical and radiologic results with autologous fat transplantation for breast augmentation: case reports and review of the literature. Breast J. 2006;12:63-5.

21. Zenn MR, Heitmann C. Extended TRAM flap: feasibility study on fresh human cadavers. Ann Plast Surg. 2003;50:256-62.

22. Harrington JL, Capizzi PJ. Cryolipolysis for nonsurgical reduction of fat in the lateral chest wall post-mastectomy. Aesthet Surg J. 2017;37(6):715-22.

23. Levine JL, Soueid NE, Allen RJ. Algorithm for autologous breast reconstruction for partial mastectomy defects. Plast Reconstr Surg. 2005;116(3):762-7.

24. Thornton DJ, le Fourie R. Autologous augmentation-mastopexy after bariatric surgery: waste not want not! Aesthetic Plast Surg. 2010;34(4):519-24.

25. Beekman WH, Hage JJ, Jorna LB, Mulder JW. Augmentation mammaplasty: the story before the silicone bag prosthesis. Ann Plast Surg. 1999:43:446-51. 
26. Oni G, Saint-Cyr M, Maia M, Wong C, Colohan S, Pessa J, Rohich R, Mojallal A. Dermolipectomy of the lateral thoracic fat compartment in secondary breast reconstruction revision: anatomical and clinical results. J Plast Reconstr Aesthet Surg. 2012;65(2):201-6.

\section{Publisher's Note}

Springer Nature remains neutral with regard to jurisdictional claims in published maps and institutional affiliations.
Ready to submit your research? Choose BMC and benefit from:

- fast, convenient online submission

- thorough peer review by experienced researchers in your field

- rapid publication on acceptance

- support for research data, including large and complex data types

- gold Open Access which fosters wider collaboration and increased citations

- maximum visibility for your research: over $100 \mathrm{M}$ website views per year

At BMC, research is always in progress.

Learn more biomedcentral.com/submissions 